\title{
World Bank renews its support for Brazil
}

[SÃO PAULO] The World Bank has approved the third phase of Brazil's Programme of Support for Scientific and Technological Development (PADCT III), which seems to have overcome recent funding problems.

PADCT functions through matching loans from the World Bank, but financial pressures previously prevented the country's Ministry of Science and Technology from passing on funds to researchers. The scheme ran into particular problems in the early 1990s during the administration of the now-impeached president Fernando Collor de Mello. Matters reached a low point for PADCT in 1992; at one point, because of its failure to provide local funds, the programme was using only 3.8 per cent of the World Bank loans.

Since then, however, the situation has improved dramatically, and the programme has become a major source of funding for many high-level research teams. It also funds attempts to remedy some of Brazil's worst regional imbalances in research support, which is currently concentrated in the southeastern states of São Paulo, Minas Gerais and Rio de Janeiro.

The latest PADCT programme also encourages the private sector to increase its spending on research, showing the influence of Brazil's science minister, Israel Vargas. Initially, PADCT III will cost US $\$ 360$ million. As before, $\$ 155$ million will come from the Brazilian government and an equal sum from the World Bank. But this time, the private sector will supply the remaining $\$ 50$ million. PADCT III is planned to end in 2001, with a total budget by then of $\$ 600$ million.
PADCT was initiated in 1984 as a way to complement the Brazilian government's internal funding for science. Although it focuses primarily on applied research, the programme also funds basic science, and particularly the importation of new procedures and techniques.

During the first phase, which lasted from 1985 to $1989,1,800$ different projects were financed by PADCT at a cost of $\$ 166.8 \mathrm{mil}-$ lion. The spending planned for the period 1990-95, on 820 projects, was $\$ 156.4$ million. A further $\$ 143.6$ million was spent in 1994-95, \$67.3 million coming from the World Bank and the rest from the Brazilian government.

But with Brazil facing heavy inflation, steering the resources through the labyrinthine Brazilian bureaucracy became a major hurdle. In particular, problems in securing local matching funds created widespread frustration, as scientists were unable to obtain money for projects that had been approved.

Things have changed since the 1992 nadir. Although red tape is still a problem, it no longer threatens research projects as it previously did. And the start of the new programme coincides with a new spirit of confidence in many parts of the Brazilian scientific community.

For example, the country has just started to operate fully a synchrotron laboratory that took several years to build, and several teams of foreign scientists are already visiting the facility (see Nature 390, 328; 1997). A supercomputer devoted to weather studies has been so productive that a second is to be bought, for installation probably later this year. And a record number of cooperation projects with foreign researchers are being carried out, ranging from tropical ocean studies to space crystallography aboard the Space Shuttle.

The only significant embarrassment has been the failure to launch the country's second indigenous scientific satellite on a domestically designed and built rocket, the VLS, last November (see Nature 390, 10; 1997). But the failure may have been more the result of bad luck than bad design, according to a report released recently.

One of the four motors of the rocket's first stage failed to ignite properly because of a fault in the device that should have detonated the propellant electrically. But a sophisticated attitude control mechanism worked perfectly, correcting the angle of the rocket after the motor had failed to ignite.

PADCT, with the World Bank's support, has played an important role in boosting morale in the research community. According to Ricardo Brentani, director of the São Paulo branch of the Ludwig Institute for Cancer Research, one major benefit is that the selection of projects is based strictly on merit, with explicit guidelines helping scientists to understand the criteria by which their requests will be judged.

The guidelines also help to prevent bias among the referees. And one interesting by-product, says Brentani, is that the questionable qualities of some prominent researchers have been exposed, and a new generation of qualified researchers all over the country acknowledged. RicardoBonalume

\section{Nanjing tops China's league for international science citations}

[TOKYO] Nanjing University in southern China is still the country's most productive source of scientific papers and has increased its lead over China's two top universities in Beijing, according to Science Citation Index figures.

The SCI's statistics, from the US-based Institute of Scientific Information, show that Nanjing, which has long emphasized basic research, published 570 SCI papers in 1996, 118 more than in the previous year.

For several years, Nanjing University has outperformed Peking and Tsinghua universities, in the northern capital of Beijing, in output of SCI papers (see Nature $378,543 ; 1995)$. And this gap has widened: Peking and Tsinghua, which rank second and third respectively, each produced just under 300 papers listed in the citation index, and increased their output only by a few tens of papers during 1995 (see table)

The figures on the numbers of SCI-listed papers produced in 1996 by universities and research institutes in China were released last month by the Chinese State Science and Technology Commission and the Chinese Institute of Scientific Information in an annual exercise that looks also at the

\begin{tabular}{|c|c|}
\hline \multicolumn{2}{|c|}{$\begin{array}{l}\text { Papers published by Chinese universities in } \\
\text { international journals in 1996* }\end{array}$} \\
\hline University & $\begin{array}{l}\text { Number of } \\
\text { papers }\end{array}$ \\
\hline 1. Nanjing & 570 \\
\hline 2. Peking & 285 \\
\hline 3. Tsinghua & 273 \\
\hline $\begin{array}{l}\text { 4. Chinese University for } \\
\text { Science \& Technology }\end{array}$ & 270 \\
\hline 5. Fudan & 230 \\
\hline 6.(jointly) Jilin & 167 \\
\hline 6.(jointly) Lanzhou & 167 \\
\hline 8. Nankai & 162 \\
\hline 9. Zhejiang & 160 \\
\hline 10. Shandong & 122 \\
\hline
\end{tabular}

number of engineering and domestic (Chinese-language) research papers.

Nanjing's comparatively high output which remains far behind the thousands of SCI papers typically produced by leading universities in the West - results from a policy of encouraging basic research. In the 1980s, the university's president Qinyue Qu, an astronomer, introduced bonuses for researchers who published SCI papers funded by local industry.

Officials at Peking and Tsinghua universities are sceptical about Nanjing's performance. They argue that it is merely the anticipated outcome of a highly targeted approach aimed at producing more research papers in international journals, and that numbers of SCI papers do not necessarily indicate the general quality or standing of a university's research output. Nevertheless, they admit that their output of SCI papers is low and needs to increase. David Swinbanks 